\title{
VICTIMIZACIÓN SECUNDARIA EN LOS SUPUESTOS DE VIOLENCIA CONTRA MUJERES INMIGRANTES EN SITUACIÓN ADMINISTRATIVA IRREGULAR*
}

\section{SECONDARY VICTIMIZATION IN CASES OF VIOLENCE AGAINST MIGRANT WOMEN IN IRREGULAR ADMINISTRATIVE SITUATION}

Víctor Merino Sancho**

Resumen: Este artículo evalúa el tratamiento jurídico de la violencia contra las mujeres inmigrantes en situación administrativa irregular a propósito de la Ley del Estatuto de la Víctima sobre la eliminación de la victimización secundaria. Con este objeto se revisa la noción de victimización secundaria para identificar los supuestos en los que se produce con la implementación de las normativas evaluadas, y en especial cuando coinciden motivos de género y de extranjería. El análisis propuesto acentúa las discordancias resultantes de la prevalencia de la condición de extranjera y la situación administrativa irregular sobre la de víctima de violencia. Frente a ello se propone reformular procedimientos existentes y nuevos modos de acceso a la justicia y los recursos y servicios de la Ley contra la violencia de género paraque sean más respetuosos con la autonomía y agencia de las víctimas.

Este trabajo se inscribe en el marco del Proyecto de Investigación "El Tratamiento de la violencia de género en la Administración de Justicia. Implementación y eficacia de la LO 1/2004" (DER2014-55400-R). Agradezco la lectura y comentarios a las primeras versiones de este trabajo a las profesoras María José Añón, Ángeles Solanes, Encarnación La Spina y Núria Torres.

** Profesor Lector de Filosofía del Derecho. Universitat Rovira i Virgili. victor.merino@urv.cat 
Palabras clave: género; inmigración; violencia contra las mujeres; victimización secundaria

Abstract: This article provides an analysis of the legal protection for violence against migrant women in an irregular administrative situation, considering the Victims' Protection Act and its prohibition of secondary victimization. With this proposal, the conceptual and legal frameworks have been reviewed considering the theoretical contributions about secondary victimization, regarding the coincidence of several positions of discrimination because of gender and a different national origin. The suggested analysis highlights the conflicts, which derives from the prevalence of the alien condition and the irregular administrative position rather than that of being victim of violence. In this article, other ways for the access to the resources and the social services established within the Law 1/2004, more respectful with the autonomy and the agency of the migrant women, are proposed.

Key words: gender; immigration; violence against women; secondary victimization

\section{INTRODUCCIÓN}

Tras la aprobación de la Ley Orgánica 1/2004, de Medidas de Protección Integral contra la Violencia de Género (desde ahora LOMPIVG), su impacto y eficacia se han valorado a partir de indicadores. Desde el primer informe anual del Observatorio Estatal de Violencia sobre la Mujer de 2007, se ha recurrido a los datos relativos al número de denuncias interpuestas y órdenes de protección reconocidas (López y Montiel: 2012: 87), haciendo referencia a momentos en los que las víctimas han decidido comunicar a las autoridades la situación de violencia que enfrentan. Si nos detenemos en la motivación que lleva a las víctimas a denunciar y sus efectos, encontramos una dimensión relevante de la que depende su actuación en la continuación del proceso y que merece una reflexión profunda; me refiero a la victimización secundaria. La victimización secundaria alude a la segunda experiencia victimal, esto es, a las consecuencias o efectos de carácter negativo que enfrentan las víctimas tras haber enfrentado un daño inicial (que precisamente las convierte en víctimas; 
victimización primaria) y que causan los órganos o agentes que intervienen en el proceso en el que se enjuicia este primer daño. Efectos que en la mayoría de ocasiones, cabe advertir, se causan de modo inconsciente.

El punto de partida de este trabajo es un análisis de la normativa contra la violencia de género y de extranjería para identificar supuestos de victimización, entendiendo además que esta es consecuencia de la situación de discriminación de los sujetos contra quienes se ejerce. A partir del mismo se proponen dos objetivos: primero, explicar qué se entiende por victimización y cómo se produce, y segundo, promover medidas que no causen dicho efecto y que sean eficaces para la protección de los derechos de las víctimas. Para ello, parto de la premisa según la cual la actual regulación contra la violencia de género es insuficiente para asegurar la protección efectiva de estos derechos cuando las víctimas son mujeres inmigrantes en situación administrativa irregular (Arnoso et alia, 2012: 170). A consecuencia de primar la condición de extranjería y una noción débil de vulnerabilidad ${ }^{1}$, la autonomía en la gestión del riesgo de las víctimas se minimiza, ocasionando una contradicción normativa en la que la mujer inmigrante en situación irregular que denuncia un acto de violencia inicia con esta misma acción un procedimiento administrativo de expulsión en su contra. Con este objeto cabe atender a lo dispuesto en la Ley de Extranjería ${ }^{2}$, tras la modificación de 2009,

1 Entiendo débil la noción que utiliza el legislador, como más tarde explico, porque coincido con Fineman (2013) cuando sostiene que recurrir a la vulnerabilidad para resaltar las situaciones de determinados colectivos puede reiterar su estigmatización si no se diferencia entre características identitarias o de estatus (Fineman 2013: 16), o si se elude la heterogeneidad de situaciones que pueden enfrentar al no explicar de forma adecuada los sistemas sociales, estructuras y relaciones que causan la discriminación (Fineman, 2011: 59), lo que no ocurre en el ordenamiento español.

2 Ley Orgánica 4/2000, de 11 de enero, sobre derechos y libertades de los extranjeros en España y su integración social (BOE n ${ }^{\circ} 10$, de 12 de enero), modificada por la Ley Orgánica 8/2000, de 22 de diciembre; por la Ley Orgánica 11/2003, de 29 de septiembre; por la Ley Orgánica 14/2003, de 20 de noviembre; por la Ley Orgánica 2/2009, de 11 de diciembre; por la Ley Orgánica 10/2011, de 27 de julio; por el Real Decreto-ley 16/2012, de 20 de abril; por la Sentencia 17/2013, de 31 de enero, del Tribunal Constitucional; por la Ley Orgánica 4/2013, de 28 de junio; por la Ley Orgánica 4/2015, de 30 de marzo y por la Sentencia del Tribunal Supremo de 10 de febrero de 2015 (en adelante LOEx) 
y la LOMPIVG 3 , tomando las disposiciones de la Ley del Estatuto de la Víctima ${ }^{4}$ como punto de referencia para determinar si existe una protección efectiva de los derechos.

\section{EL CONTEXTO DE VIOLENCIA DE GÉNERO EN EL ESTADO ESPAÑOL}

La condición de inmigrante de las mujeres contra quienes se ejerce esta violencia añade a la complejidad que per se presenta el fenómeno violento una variable relevante, máxime según se desprende de sus índices de prevalencia sobre este colectivo. Los datos cuantitativos que señalan informes oficiales en España, sin que se distinga la situación administrativa de las víctimas, manifiestan una incidencia proporcionalmente mayor en este sector poblacional, que en ocasiones adquiere cotas de sobrerrepresentación (Morillas, Patró y Aguilar 2014: 478-480), dado que la población extranjera en territorio suele representar alrededor del 10-12\% de la población residente según los datos del Instituto Nacional de Estadística ${ }^{5}$. Estas cifras exponen que en 2007, de 75 homicidios, 32 fueron cometidos contra mujeres extranjeras, siendo 49 cometidos por españoles y 26 extranjeros. En 2008, se incrementó la cifra de víctimas mortales extranjeras hasta 39 de un total de 74 muertes. Respecto a los agresores, 31 eran extranjeros frente a 43 españoles. En los años siguientes, las cifras de víctimas mortales se reducen, aunque no el porcentaje de extranjeras; así, en 2013, de un total de 54 víctimas hubo 16 extranjeras, y 17 de 54 en 2014. En 2015 aumentó el número de víctimas a 60 , de las cuales 22 eran extranjeras, siendo menor el porcentaje de agresores con origen extranjero puesto que solo 16 no tenían nacionalidad española ${ }^{6}$.

3 Ley Orgánica 1/2004, de 28 de diciembre, de Medidas de Protección Integral contra la Violencia de género (BOE núm. 313, de 29 de diciembre de 2004).

4 Ley 4/2015, de 27 de abril, del Estatuto de la víctima del delito (BOE núm. 101, de 28 de abril).

5 INE: http://www.ine.es/inebaseDYN/cp30321/cp_inicio.htm (última consulta: 31 de marzo de 2016)

6 Los datos sobre violencia de género se publican trimestralmente en informes y estadísticas del Observatorio Estatal contra la Violencia de Género. Pueden encontrarse en:

http://www.violenciagenero.msssi.gob.es/violenciaEnCifras/home.htm (última fecha de consulta: 9 de junio de 2016). 
Según los informes del Observatorio contra la violencia doméstica y de género del Consejo General del Poder Judicial ${ }^{7}$, en 2015 hubo un total de 129.193 denuncias por violencia de género, de las cuales en $37.261(30,1 \%)$ aparecen como víctimas mujeres extranjeras, siendo este un porcentaje similar a los anteriormente mencionados. Sin embargo, en el informe de 2013 del Observatorio se contempla otro indicador que considero sumamente relevante. Se trata del dato relativo al número de víctimas que se acogen a la Renta Activa de Inserción, que no refleja una tendencia semejante a las anteriores, siendo consciente que las condiciones para acogerse a ella pueden depender de factores de diversa índole (Arnoso et alia, 2012: 178179). De hecho, en 2006 un 86,6\% de las titulares tienen nacionalidad española frente a un $13,3 \%$ de extranjeras. No obstante, esta tendencia va convergiendo con las cifras sobre víctimas y en 2013 un $75,2 \%$ de las titulares son españolas y un $24,8 \%$ extranjeras.

No ocurre lo mismo con relación a la ayuda económica prevista en el artículo 27 de la LOMPIVG para víctimas de violencia, que se distribuye en este mismo período de forma uniforme puesto que en 2006 se concede el $85 \%$ de las mismas a víctimas nacionales frente al $15 \%$ a inmigrantes y en 2013 , un $82,9 \%$ - $17,1 \%$ respectivamente. Ambos indicadores ponen de manifiesto que pese a que el porcentaje de víctimas extranjeras se sitúa alrededor del 30\%: 1) solo la mitad reciben esta ayuda, y 2) que, aunque se va aproximando, sigue siendo menor el porcentaje de mujeres extranjeras que se acogen a la Renta Activa de Inserción. Estos índices instan a reflexionar acerca de dicha sobrerrepresentación y el diferente acceso de las víctimas a las ayudas, servicios y recursos establecidos en la LOMPIVG. Por esta misma razón, deben ser tenidos en cuenta para promover un marco jurídico adecuado de modo que no se soslaye la multidimensionalidad del fenómeno violento ni tampoco la situación de algunos colectivos, especialmente cuando ello les impide acceder a los recursos y servicios previstos en la normativa, siendo contrario a sus propias disposiciones.

7 Los informes y datos que el Observatorio contra la violencia doméstica y de género del Consejo General del Poder Judicial se pueden encontrar en:

http://www.poderjudicial.es/cgpj/es/Temas/Violencia-domestica-y-de-genero/ El-Observatorio-contra-la-violencia-domestica-y-de-genero/ (última fecha de consulta: 9 de junio de 2016). 


\section{SOBRE LA VICTIMIZACIÓN SECUNDARIA}

La victimización secundaria es un concepto que surge de la reflexión sobre el estatuto de las víctimas en los procesos judiciales tras la tipificación de la violencia sexual. A pesar de las singularidades de este delito, su previsión inicial en los códigos penales no comporta la modificación de las normas procesales ni de la orientación de los procesos judiciales que únicamente pretenden constatar los hechos para determinar la responsabilidad penal de los agresores (Pitch, 2003). En este escenario, las víctimas intervienen casi exclusivamente para relatar los hechos postergando sus propios intereses (Gutiérrez, Coronel y Andrés, 2009: 50), siendo sus comportamientos examinados y cuestionados, además de ser interpeladas solo porque de su testimonio depende el castigo (Larrauri, 2007: 37-38).

La victimización secundaria se refiere a las consecuencias o efectos negativos de índole psicológica, social, económica y jurídica que tiene para la víctima interactuar con el ordenamiento jurídico o su participación en procesos judiciales (Gutiérrez, Coronel y Andrés, 2009: 52), causados por parte de los operadores que participan e intervienen en los mismos, los servicios relacionados con las víctimas (como ahora las oficinas de atención a las víctimas del delito o los médicos forenses...), así como otros agentes externos, como medios de comunicación o actores no directamente implicados (Tamarit, 2013: 274). Por todo ello se ha entendido como una "segunda experiencia victimal" que se ocasiona en un contexto institucional que por el contrario debe proteger sus derechos e intereses (Gutiérrez, Coronel y Andrés, 2009: 50).

A este respecto, se han objetado al Derecho dos críticas al entender que también las normas pueden causar dicha victimización. En primer lugar, la propia configuración de los tipos penales se basa en imágenes, representaciones y estereotipos que causan efectos negativos o discriminatorios en las víctimas. Esto ocurre en los delitos de agresión sexual y violencia en la pareja (Maqueda, 2008: 367), cuando se exige a la víctima demostrar que ha tenido un comportamiento adecuado y no ha quebrado la normatividad que rige la sexualidad, sin que se cuestionen las nociones y significados sobre los que se sostiene el Derecho cuando son discriminatorios (Pitch, 2003: 209). En segundo, que las normas procesales se orientan a la determinación del daño y no a su reparación (Pitch, 2003: 191). 
Sin embargo, en los últimos años se ha promovido un cambio en la consideración del papel de las víctimas que se ha traducido en nuevas normas procesales, fundamentalmente con la adopción de la Directiva 2012/29/UE del Parlamento Europeo y del Consejo de 25 de octubre de 2012, por la que se establecen normas mínimas sobre los derechos, el apoyo y la protección de las víctimas de delitos, y en el ordenamiento español de la Ley 4/2015, de 27 de abril, del Estatuto de la Víctima, que inician una tendencia en la que la protección de los derechos, intereses y situaciones personales de las víctimas adquiere mayor relevancia. Según ambas disposiciones, las normas y las actuaciones de los operadores jurídicos y agentes que intervienen o tienen contacto con las víctimas deben orientarse a aumentar la confianza de estas últimas en las autoridades y garantizar su efectivo acceso a la justicia bajo la prohibición expresa de causar victimización secundaria. En mi opinión, esto solo es posible si se toman en consideración los efectos que un proceso puede tener en la víctima, bien por ser víctima directa de una conducta gravosa que debe ser enjuiciada, bien por participar en un proceso institucionalizado en el que se valora la conducta del agresor/victimario y la gestión de sus conductas pasadas y futuras (Morillas, Patró y Aguilar, 2014: 15). En razón de este nuevo marco, existen motivos suficientes para remover cualquier supuesto de victimización secundaria en el marco normativo y/o derivado de las prácticas de los poderes públicos.

\subsection{Victimización secundaria por motivos de género}

Según esta noción de victimización secundaria, las normas o instituciones socio-jurídicas pueden causar otra experiencia victimal a quienes han sido víctimas por una conducta delictiva. Considero oportuno discernir ahora si puede ser debida a motivos de género y de ser así, si tiene vinculación con la discriminación por este motivo. Adelanto que, a mi juicio, esta relación se pone de manifiesto cuando normas y prácticas se sustentan en nociones y normatividades de género que reproducen la discriminación/subordinación. En cualquier caso, la noción de género no implica que todos los sujetos ocupen posiciones de subordinación, ni mucho menos las mismas, ni que hagan frente a idénticas consecuencias, porque el género no puede entenderse de forma unívoca ni homogénea (Añón, 2016).

En este sentido, el legislador español opta por reducir el contenido del concepto de violencia de género en el marco normativo al 
precisar que es "manifestación de la discriminación, la situación de desigualdad y las relaciones de poder de los hombres sobre las mujeres" (Preámbulo LOMPIVG), y "se ejerce sobre éstas por parte de quienes sean o hayan sido sus cónyuges o de quienes estén o hayan estado ligados a ellas por relaciones similares de afectividad, aun sin convivencia" (artículo 1.1 LOMPIVG). Se trata por tanto de una concepción restrictiva que se caracteriza por ejercerse contra una mujer siempre que haya o haya habido una relación de afectividad, excluyendo cualquier otro acto violento basado en el género. Es decir, la violencia de género según el legislador español es resultado de relaciones de poder desiguales pero solo lo es la violencia en la pareja (Añón, 2016: 8).

En mi opinión, en la comisión y enjuiciamiento de estas conductas violentas, victimización primaria y secundaria responden a motivos de género. En relación con la primera, porque el acto violento es definido como tal si constituye una conducta gravosa motivada por la pertenencia al género femenino. En el ordenamiento español, solo si ha habido una relación de afectividad, lo que caracteriza todavía más esta situación puesto que la víctima puede haber experimentado una exposición reiterada a la violencia por parte de una misma persona con la que mantiene o ha mantenido una relación de afectividad. En relación con la segunda, porque la discriminación estructural de la que surge la victimización secundaria se define como un trato desigual basado en "estructuras de subordinación y resultados sistemáticamente desventajosos para ciertos grupos, incluso en ausencia de motivos discriminatorios explícitos" (Añón, 2013: 148).

En este caso, nociones e identidades de género que crean unas determinadas relaciones de poder/subordinación hacen que los órganos que intervienen en un proceso o que interactúan con la víctima compartan, ejerzan y (re)produzcan estas mismas dinámicas sociales, frecuentemente sin ser conscientes de reproducirlas. Esto dificulta la erradicación de la discriminación y de la victimización puesto que, de acuerdo con Barrère y Morondo, se caracteriza por ser estructural, social, sistémica y difusa, y se manifiesta de forma diversa en distintos ámbitos sociales. Así ocurre con la normativa procesal y la interacción de los individuos con las instituciones socio-jurídicas (Barrère y Morondo, 2005: 151 y 158).

En un contexto de disposiciones normativas y prácticas institucionales en las que las víctimas por violencia pueden enfrontar situaciones de victimización secundaria, destaca el supuesto de la 
indeterminación que sigue habiendo en el ordenamiento procesal acerca de si la víctima de violencia puede acogerse a la dispensa a la obligación de declarar como testigo (artículo 416 LECrim) sin que ello suponga el sobreseimiento del caso, así como si las declaraciones iniciales en fase sumarial pueden ser válidas a efectos probatorios en fase de juicio oral cuando se ha acogido a la dispensa anterior (Montesinos 2012: 403). Especialmente, resulta contradictorio y constituye un supuesto de victimización permitir la dispensa a la víctima si a continuación se absuelve al agresor justamente por falta de pruebas (Larrauri 2005: p. 167), sin tener en cuenta que las normas procesales reconocen la posibilidad de reproducir en el juicio oral las declaraciones realizadas por víctimas y otros testigos en fase sumarial de acuerdo con lo dispuesto en los artículos 714 y 730 LECrim (Montesinos 2012: 409).

\subsection{Victimización secundaria en personas inmigrantes en situación administrativa irregular}

Como ocurre con la victimización secundaria por razón de género, la condición de inmigrante, y en concreto la normativa y la práctica institucional al respecto se han señalado como origen y causa de victimización, también debida en parte a la discriminación estructural. Esta discriminación se evidencia no solo en la praxis de los agentes institucionales que interactúan con ellos y los representa como un colectivo homogéneo, obviando las múltiples diferencias que pueden existir ad intra, sino también a consecuencia de la legislación de extranjería, los discursos y las prácticas sociales que emergen de una noción basada en la otredad y su control que contradicen el paradigma de la igualdad de derechos (de Lucas, 2004: 30 y 31). Como señalaba en el epígrafe anterior, la condición de inmigrante tampoco sitúa de una misma forma a los sujetos en las relaciones socio-jurídicas, por ejemplo porque concurran otras dimensiones como el género, la orientación sexual, la clase social o la edad.

En este escenario, existen diversos supuestos de victimización secundaria de las personas migrantes a consecuencia del marco normativo de extranjería que merecen un análisis más específico que el que aquí puede realizarse, sobre todo si se atiende a la complejidad y heterogeneidad de situaciones a que puede dar lugar. Entre otros, pueden destacarse los supuestos de discriminación por irregularidad sobrevenida (Solanes, 2006), y si se introduce el género, los 
supuestos de discriminación contra mujeres migrantes en el ámbito laboral (Parella, 2003), por razón de la regulación de la reagrupación familiar o la respuesta del ordenamiento a las demandas de asilo por motivos de género (La Spina y Merino, 2012), así como la ausencia de protección efectiva de las víctimas en los supuestos de trata (Villacampa y Torres, 2012). Más grave es, si cabe, la situación de las mujeres inmigrantes privadas de libertad en los Centros de Internamiento (Women's link Worldwide, 2012).

En concreto, me detengo en los supuestos de irregularidad administrativa y la victimización secundaria producida por la normativa, las instituciones y los agentes socio-jurídicos (Pereda y Tamarit, 2013: p. 274). El legislador distingue entre inmigrantes en situación administrativa regular e irregular y sitúa a estos últimos fuera de la legalidad, alejándolos de la condición de sujeto político y por tanto de derechos (de Lucas, 2004). La existencia de mecanismos de regularización tienden a gestionar los flujos migratorios mediante estrategias y dispositivos que aseguran el control de los extranjeros al situarlos en condiciones de vulnerabilidad y discriminación. En definitiva, se institucionaliza la exclusión de los inmigrantes del espacio público (De Lucas, 2005: 214-216), cuando el legislador considera que la inmigración "irregular" es una amenaza grave y prevalece su erradicación frente a cualquier otro interés, incluso el de su regularización (Solanes, 2015: 14).

Por esta razón quienes escapan de dicho control y de la lógica que estas medidas imponen son representados como sujetos que infringen el derecho y a quienes se les dificulta el proceso de regularización cuando no se les expulsa directamente (Fischer, 2013). El inicio de un expediente sancionador administrativo sitúa a los inmigrantes irregulares en una posición que les impide acceder a la estabilización o desarrollar estrategias de regularización aun cuando todavía no hayan sido expulsados, lo que debiera ser el objeto de las medidas que se adoptan (Solanes, 2006: 20). En ocasiones se llega a rebajar el sistema de protección social que caracteriza a algunos ordenamientos jurídicos con objeto de promover la falta de aspiraciones y deseos de permanecer en territorio nacional (Ugelvik y Ugelvik, 2013). En definitiva, la extranjería es el elemento distintivo que viene a justificar dichas discriminaciones a la baja.

En relación con los factores que confluyen en lo que se ha denominado "el aislamiento migratorio" (Acale, 2007), que influyen en la situación de discriminación de los inmigrantes y que pueden causar 
victimización, cabe tener en cuenta: la vinculación o no con los permisos de residencia del cónyuge o persona con las que se mantenga una situación análoga a la conyugal (Martínez, 2008); y con independencia del estatuto administrativo y en menor medida el género, la inexistencia de redes sociales (Arnoso et alia, 2012: 182); las dificultades idiomáticas, la desconfianza de las Fuerzas y Cuerpos de seguridad del Estado (García et alia, 2013); y el desconocimiento de la legislación del país de recepción (Acale, 2007) así como de las consecuencias de iniciar un procedimiento judicial (SOS Racismo, 2015).

Además, un análisis conjunto del derecho penal y la normativa de extranjería pone de manifiesto que existen medidas orientadas a castigar de un modo diferente a las personas inmigrantes (sin que el género sea un elemento relevante), e incluso que el derecho penal es utilizado para su exclusión (Larrauri, 2016: 5). Entre otras, la posibilidad de ser expulsado como una medida punitiva por la comisión de un delito tras sentencia firme en determinados supuestos, con independencia del estatuto regular o irregular (artículo 89 del Código Penal), y la expulsión por infracción administrativa grave o muy grave, como es hallarse en situación administrativa irregular en territorio nacional (artículo 53 y 57 de la LOEX). Aunque cada una de estas medidas merecen, y han justificado, una reflexión en mayor profundidad, interesa aquí resaltar que en ambos casos se imponen algunas que obvian el sentido, la naturaleza y la finalidad constitucional de las penas (Salinero, 2011: 132-133), y en materia sancionadora administrativa, se equipara la permanencia en territorio nacional sin autorización a la comisión de conductas graves (Larrauri, 2016: 23).

\section{LA VICTIMIZACIÓN SECUNDARIA DE LAS MUJERES MIGRANTES EN SITUACIÓN ADMINISTRATIVA IRREGULAR EN LA LOEX}

Decía antes que la victimización secundaria se entiende como resultado de la situación de discriminación/subordinación por razón de ser víctima de violencia de género y la condición de inmigrante. Aunque me ciña al supuesto de violencia según lo define la LOMPIVG, conviene recordar que la victimización no sólo se produce en este supuesto. En este sentido, es oportuno recurrir a la noción de 
interseccionalidad (Crenshaw, 1996). La interseccionalidad es una herramienta analítica que permite mostrar cómo la intersección de caracteres sociales influye y modifica la forma en la que se vive una y otra. Es decir, cuando género y origen nacional coinciden, la discriminación estructural a la que hace frente las mujeres inmigrantes es diferente y más compleja que la que enfrentan las mujeres por razón de género y los hombres inmigrantes por su distinto origen nacional. En ambos, las inmigrantes ocupan posiciones de discriminación y la situación final es cualitativamente diferente que la que viven los sujetos anteriores (Crenshaw, 1996: 372).

En este orden, debe asumirse que el marco jurídico aplicable a los supuestos de violencia no debe eludir la heterogeneidad de experiencias y proyectos migratorios que sitúan a las mujeres migrantes -y construyen sus identidades- en el discurso y en el plano jurídico (Añón, 2010: 107-108). Al respecto, el legislador ha calificado de forma explícita la situación de las mujeres inmigrantes de "especial vulnerabilidad" frente a la violencia de género en la LOMPIVG, sin distinguir su estatuto. Decía al comienzo que esta es una noción débil porque si bien identifica dichos grupos, no hay ninguna referencia a los sistemas sociales, políticos y materiales que causan esta situación, lo que puede ocasionar mayor estigmatización de estos colectivos (Fineman, 2011: 59). Así mismo, Fineman propone una noción de vulnerabilidad universal que requiere identificar las situaciones, el significado y el valor político que los sistemas sociales, y esto implica leyes y acciones de las instituciones, otorgan a los grupos en situación de subordinación creando una distribución de poder, privilegios y discriminación que requiere de medidas más allá del principio de igualdad de oportunidades. Además, ella cuestiona que la interseccionalidad sitúe al individuo en la intersección de identidades y no en la intersección de sistemas sociales (Fineman, 2011: 60) Por este motivo considero oportuno recurrir a la interseccionalidad en el sentido propuesto por Crenshaw y las apreciaciones sugeridas por Fineman, distinguiendo los sistemas, las estructuras y las relaciones que causan discriminación por género y origen nacional, y los cambios que puede haber cuando estos sistemas se entrecruzan.

El sentido que el legislador otorga a este concepto, previsto también para las mujeres con movilidad funcional diferenciada, es el de sobreexposición a la violencia (Monteros, 2008: 242). En consecuencia, la LOMPIVG prevé dos cláusulas generales pensadas para hacer 
frente a este supuesto y que arbitran el principio de igualdad. La primera se establece en el artículo 17.1, referido al reconocimiento de los derechos establecidos en la ley a todas las mujeres víctimas de violencia de género, con independencia de su origen, religión u otra condición. En cambio, la segunda deriva de los artículos 30.1 y 32.4, que arbitran un trato especial según estas mismas circunstancias al entender que hay un mayor riesgo de enfrentarse a esta violencia o mayores dificultades en el acceso a los servicios y recursos previstos en la ley. En virtud de este último, el legislador mismo deslegitima cualquier impedimento en su acceso.

A pesar de ello, de la aplicación conjunta de las normativas contra la violencia y de extranjería se causa victimización secundaria. La LOMPIVG exige la denuncia de una situación de violencia para obtener protección y garantizar el acceso a los servicios y los recursos, mientras que si se denuncia dicha situación se pone en conocimiento de las autoridades la irregularidad y debe iniciarse de lege lata un procedimiento sancionador de expulsión según la LOEx. A mi parecer, esta previsión elude los efectos que se derivan de dicha normativa y/o de la praxis de los operadores o agentes, siendo uno de los ejemplos claros de victimización secundaria de víctimas de violencia de género inmigrantes en situación administrativa irregular (Rubio y Moya, 2011).

En la normativa de extranjería anterior a la reforma de 2009, la violencia de género sobre mujeres inmigrantes en situación irregular no se mencionaba en ninguna disposición (Acale, 2006). En este supuesto y aquellos en los que se quebraban permisos de residencia dependientes de los maridos se aplicaba la autorización de residencia temporal por razones humanitarias (López, 2013). No obstante, se producía la antinomia jurídica referida; con la denuncia que iniciaba un proceso penal por violencia, las autoridades policiales se veían impelidas a iniciar un procedimiento de expulsión de acuerdo con la normativa de extranjería que no preveía ninguna excepción ${ }^{8}$. En este escenario, mientras el primero garantizaba la protección de sus derechos como víctima, el segundo podía resolver la expulsión

8 La Instrucción 14/2005 de la Secretaría de Estado de Seguridad sobre actuación de dependencias policiales en relación con mujeres extranjeras víctimas de violencia doméstica o de género en situación administrativa irregular dispuso la preceptiva incoación del expediente sancionador con motivo de la irregularidad de la mujer extranjera víctima de violencia de género. 
de la víctima del territorio español por su situación administrativa, a pesar de las previsiones de la LOMPIVG, y que la violencia era una infracción penal y la situación administrativa irregular una infracción administrativa.

Esta preeminencia de la condición de irregularidad sobre la de víctima ha sido matizada con la reforma de 2009 de la LOEx ${ }^{9}$. Esta modificación trata de resolver esta contradicción al supeditar el procedimiento por irregularidad administrativa al resultado del proceso por violencia, aunque en realidad solo posterga el procedimiento administrativo. El artículo 31 bis de la LOEx regula este supuesto reiterando las medidas del art. 17.1 de la LOMPIVG, con independencia de la situación administrativa de las inmigrantes, y en su apartado segundo dispone que en caso de denuncia de violencia por parte de una mujer inmigrante en situación irregular procede la preceptiva suspensión del procedimiento de expulsión, que queda supeditado a la resolución del proceso penal. Esta regulación dispone la suspensión automática del proceso de expulsión arbitrada en términos y en unas condiciones aparentemente más acordes a la protección de los derechos de las víctimas (ex art. $131 \operatorname{ReLOEx}^{10}$ ). Sin embargo, se mantiene una protección endeble y una solución jurídica temporal, porque la respuesta para esta violencia sigue siendo "una autorización de residencia y trabajo por circunstancias excepcionales". Con objeto de garantizar una protección más inmediata, se prevé la concesión de una autorización provisional con la interposición de la denuncia por violencia (art. 132 ReLOEx).

No obstante estos cambios, considero que no se supera el carácter temporal de la protección que se concede bajo la premisa de la excepcionalidad, cuya tramitación se retoma tras la decisión penal si esta no es condenatoria. Con mayor razón, cuando el número de autorizaciones de residencia temporal para víctimas que no tienen

9 Con la Ley Orgánica 2/2009, de 11 de diciembre, de reforma de la Ley Orgánica 4/2000, de 11 de enero, sobre derechos y libertades de los extranjeros en España y su integración social, BOE n ${ }^{\circ} 299$, de 12 de diciembre de 2009, se añade un nuevo artículo 31 bis, sobre residencia temporal y trabajo de mujeres extranjeras víctimas de violencia de género.

10 Real Decreto 557/2011, de 20 de abril, por el que se aprueba el Reglamento de la Ley Orgánica 4/2000, sobre derechos y libertades de los extranjeros en España y su integración social, tras su reforma por Ley Orgánica 2/2009, BOE $\mathrm{n}^{\circ} 103$, de 30 de abril de 2011, texto consolidado de 15 de marzo de 2014 (en adelante ReLOEx). 
un permiso de residencia regular o independiente es muy elevado. Las cifras van desde las 2 autorizaciones concedidas en 2005 hasta las 1.874 de 2012. A partir de entonces, el número desciende a 1.249 en 2015, según datos del Observatorio Estatal de Violencia contra la Mujer, pero conviene destacar que, según señala en su Informe de 2013, las autorizaciones suelen reconocerse en un 74,8\% de las ocasiones, lo que a su vez pone de manifiesto la persistencia de la violencia contra mujeres en situación administrativa irregular.

Otro aspecto relevante a destacar acerca de esta protección es la posible conculcación del derecho fundamental a una tutela judicial efectiva ${ }^{11}$. En la regulación vigente no se específica si la sentencia condenatoria debe tener carácter firme (arts. 133 y 134 ReLOEx), lo que puede inducir a que el procedimiento de expulsión se reinicie aun cuando no exista sentencia firme en el proceso penal por violencia. Tampoco se exige dicha firmeza para que dejen de surtir efecto las medidas provisionales anteriores, salvo que de acuerdo con la doctrina constitucional se entienda como finalización del proceso la existencia de una sentencia firme ${ }^{12}$.

Si el temor a ser expulsada comporta el rechazo por parte de las víctimas a iniciar dicho procedimiento de denuncia, se está restringiendo el acceso a recursos y derechos que dispone la LOMPIVG para las víctimas de violencia, causando así victimización secundaria. Constituyen dos ejemplos claros los mencionados Real Decreto 1425/2005, de 2 de diciembre que arbitra la ayuda económica específica para víctimas de violencia prevista en el art. 27 LOMPIVG y el Real Decreto 1369/2006, de 24 de noviembre que regula el programa de renta activa de inserción para desempleados, entre cuyos supuestos

11 Su desconocimiento ha provocado que no se reconociese en primera instancia esta posibilidad, incluso cuando la indeterminación de los plazos ha sido motivo de sentencia en casos en los que el proceso penal había acabado con una sentencia condenatoria. Así sucede en la Sentencia núm. 343/2013, de 25 de noviembre, del Juzgado de lo Contencioso-Administrativo núm. 1 de Lleida.

12 Como viene interpretando el Tribunal Constitucional, es doctrina consolidada entender que la ejecución de las sentencias debe efectuarse si y solo si tienen carácter firme, lo cual, según afirma el Tribunal forma parte del contenido del derecho a la tutela judicial efectiva. A fortiori, en esta normativa, y según esta doctrina, la locución "hasta la finalización del proceso penal" significa que se continuará el procedimiento administrativo sancionador por la infracción del art. 53.1.a) de la Ley 4/2000, según el art. 134.2.c) ReLOEx. Así lo señala el Dictamen del Consejo de Estado al borrador del Reglamento. 
se incluyen las víctimas de violencia. Estas dos ayudas requieren formas de acreditación diferentes. La primera exige el reconocimiento de la situación de violencia mediante una orden de protección o con carácter excepcional del informe del Ministerio Fiscal. En la segunda, se contempla una remisión general a la autoridad competente para acreditar dicha situación, lo que evidencia la preeminencia otorgada a la judicialización de la gestión del conflicto. En esta última, además, se requiere un Informe del Servicio Público de Empleo que acredite "tener dificultades especiales para obtener un empleo". A pesar de no ser un documento judicial, cabe advertir, su obtención es igualmente un obstáculo para una persona que reside en un país de forma irregular. Pensemos que una mujer en esta situación difícilmente puede acreditar dicho aspecto cuando la principal dificultad para obtener empleo es la misma situación de irregularidad (Arnoso et alia, 2012: 181). En definitiva, el impedimento en el acceso a los recursos y derechos lo constituye el estatus que otorga la ley.

De lo anterior se desprende que las estrategias de protección y seguridad y el respeto de los derechos de las víctimas dependen en mayor medida de la regulación de extranjería que de la normativa para la eliminación de la violencia. Las disposiciones de esta última provocan que la capacidad de decisión sobre la gestión del fenómeno violento se desplace de la mujer-agente al Estado protector, sin que la víctima (independientemente del origen nacional) intervenga de forma activa. En segundo lugar, el temor (fundado) a un proceso de expulsión con la denuncia crea indefensión e inseguridad, y por tanto victimización secundaria. Con todo, de ello no debe inferirse que se pretenda aquí la desjudicialización de la violencia, sino combatir esta victimización y proponer otras medidas para fomentar la autonomía de quienes han visto conculcados sus derechos.

\section{MEDIDAS PROPUESTAS PARA EVITAR LA VICTIMIZACIÓN SECUNDARIA DE MUJERES EXTRANJERAS EN SITUACIÓN ADMINISTRATIVA IRREGULAR}

Por las razones expuestas con anterioridad creo oportuno proponer medidas que no causen victimización secundaria, especialmente por ser contrarias a la normativa de protección de víctimas. En este contexto, se propone en lo que sigue una serie de medidas que tienden a garantizar el respeto de sus derechos. Medidas que por otra 
parte pretenden devenir en razones para una reflexión ulterior y más general acerca de la normativa contra la violencia de género tras la entrada en vigor de la Ley del Estatuto de Víctimas.

\section{a) Propuestas de lege ferenda}

De las críticas anteriormente señaladas se desprende que existen motivos suficientes para derogar las disposiciones que exigen incoar dicho expediente en los supuestos estudiados. Asimismo, se proponen otras medidas con objeto de promover la regularización de estas víctimas y el respeto a su autonomía. Una de ellas tiene que ver con la consideración de la situación de violencia de género como posibilidad para el arraigo como vía de estabilización (Rueda, 2008). El arraigo constituye una vía de regularización que presume la irregularidad y que no la sanciona de forma negativa (Solanes, 2006), ofreciendo así una mayor seguridad para la solicitante por diversas razones. De un lado, de él no se infiere el inicio del procedimiento de expulsión. Se trata de un mecanismo que constata la residencia o permanencia en el territorio y cuyos requisitos pueden tener en cuenta situaciones particulares, como este tipo de violencia. De otro, porque con esta medida se soslaya el carácter excepcional que impregna la autorización de residencia por motivos humanitarios. Idea que persiste en la normativa vigente en relación con las autorizaciones de residencia temporal y trabajo según su tenor literal.

b) Propuestas de medidas de acreditación del Ministerio Fiscal

Dado que la última modificación legislativa muestra la persistencia de la lógica de control de la irregularidad y que la denuncia da lugar a victimización secundaria, creo oportuno reflexionar sobre el procedimiento para reconocer la situación de violencia de forma que se combata dicha lógica. En un plano propositivo, planteo la posibilidad de reconocer efectos jurídicos a los informes emitidos por el Ministerio Fiscal sin que tengan carácter excepcional, y propongo que se admitan las certificaciones de las Unidades de Valoración Integral y los Servicios de Atención a la Víctima del Delito, de modo que sean susceptibles y suficientes para constatar los indicios de una situación de violencia y permitir a las víctimas acceder a los recursos y servicios que ahora solo les posibilita la orden de protección.

El Ministerio Fiscal puede acreditar de forma excepcional la situación de violencia de la víctima, de acuerdo con lo dispuesto en el Real Decreto sobre la ayuda económica a las víctimas de violencia 
de género. Esta posibilidad es una cuestión controvertida desde la aprobación de la LOMPIVG, porque el legislador optó por condicionar la protección de la víctima a jueces y tribunales, permitiendo de modo excepcional dar validez a la acreditación de la situación de violencia por parte del Ministerio Fiscal en los supuestos de acceso a ayudas y servicios sociales (Peramato, 2015: 13). En este sentido, la Fiscalía General del Estado emite en 2005 la Instrucción 2/2005 sobre la acreditación por el Ministerio Fiscal de las situaciones de violencia de género, en la que se unifican los criterios de actuación del Ministerio Fiscal para acreditarlas. De este documento se concluye que dicha acreditación se justifica en motivos de urgencia y constituye un título a efectos solo de obtener los derechos e instrumentos de protección social establecidos en el ámbito laboral, de seguridad social, funcionarial o social (Capítulos II, III y IV de la LOMPIVG). Según la Instrucción se trata de medidas que permiten promover la capacidad de respuesta de la víctima frente a la situación de violencia y no se condicionan a la obtención de una orden de protección aunque sí a su solicitud.

Por su parte, la Circular 6/2011 sobre criterios para la unidad de actuación especializada del Ministerio Fiscal en relación a la violencia sobre la mujer hace referencia a los supuestos de violencia de género contra una mujer extranjera en situación administrativa irregular. En este sentido, se alude al artículo 31 bis de la LOEx y reitera el carácter excepcional de la acreditación de la situación de violencia por parte del Ministerio Fiscal, supeditada a la inminencia del riesgo de acuerdo con la Instrucción 2/2005. A pesar de no haber referencia alguna al deber de incoar el procedimiento administrativo de expulsión, de la literalidad de la circular se intuye que el Ministerio Fiscal acredita solamente la situación de violencia, aunque las autoridades policiales suelen ser quienes inician dicho expediente sancionador. Destaca sin embargo la conclusión decimosexta, en la que se indica que en los supuestos de mujeres extranjeras irregulares o reagrupadas víctimas de violencia de género, la acreditación del Fiscal de la existencia de indicios de dicha violencia, podrá ser emitida aun cuando no se haya interesado orden de protección y sin necesidad de valorar la existencia de indicios objetivos de riesgo.

Así, la acreditación por parte del Ministerio Fiscal es posible, en tanto que ya se ha asumido esta tarea para que la víctima pueda acceder a los recursos y servicios previstos por la LOMPIVG. El objeto principal de este reconocimiento es garantizar la seguridad más 
inmediata a la víctima y sobre todo el acceso efectivo a recursos y derechos que la garanticen y la continuación del proceso por violencia, bajo las premisas del respeto a la autonomía de la víctima y a los derechos del presunto agresor. Por esta razón, en este informe acreditativo de la violencia no deben adoptarse medidas restrictivas de derechos, sino reconocer la posibilidad de acceso a servicios de protección, como pisos de acogida o residencias seguras, y servicios y recursos previstos para las víctimas.

c) Propuestas de medidas de acreditación de la violencia alternativas por parte de las Unidades de Valoración Integral y Servicios de Atención a la Víctima y otras entidades

Si se otorga validez a los informes de las Unidades de Valoración Integral y los Servicios de Atención a la Víctima, estos podrían contener datos más precisos acerca de las dimensiones que median en la comisión del acto concreto, y se daría cumplimiento a la exigencia de no condicionar el acceso a estos servicios a una denuncia previa, de acuerdo con el art. 28.3 de la Ley del Estatuto de la Víctima. El carácter formal de las respuestas para combatir la violencia se mantienen si se considera la participación de estas entidades por diversos motivos. Primero, porque las unidades de valoración y/o los servicios de atención a la víctima son órganos de naturaleza interdisciplinar que pretenden fomentar la autonomía, mediante la información que facilita a las víctimas (Ibáñez, 2012: 437). Segundo, porque su finalidad es constatar la situación de violencia, independientemente de la situación administrativa, y solo para acceder a los recursos sociales. Es decir, se trataría de certificados que no tendrían carácter probatorio en fase oral, ni efectos frente a terceros, salvo los servicios y recursos a los que se accedería. Tercero, porque no son órganos de control en el mismo sentido que los órganos policiales, y por esta misma razón generan mayor confianza en las víctimas al no hacer prevalecer su condición de extranjera.

Decía que la acreditación en estos casos persigue una protección inmediata y el acceso a los recursos. Si existe una primera fase en la que se decide este aspecto, sin que exista riego de expulsión, no se coarta la decisión de la víctima por dicho temor. Además se fomenta así la intervención proactiva de los poderes públicos y de los colectivos y asociaciones de migrantes, a los que me refiero a continuación, en una fase en la que el fenómeno violento ha ocurrido o es temido porque existen indicios suficientes de su comisión. 
En este orden, debe haber una reflexión hacia la posible acreditación de la violencia por otras entidades, fundaciones y asociaciones, como ONGs institucionalizadas o con competencias en materia de extranjería por diversas razones. Principalmente porque la articulación de otros tipos de reconocimiento de situaciones de vulnerabilidad fuera del ámbito judicial es posible. Así lo explica La Spina cuando detalla cómo los informes de idoneidad de la vivienda requeridos en el procedimiento de reagrupación familiar son emitidos por entidades diversas de carácter comunitario (La Spina, 2009: 74). Con todo, soy consciente de la complejidad de dicha iniciativa para los casos de violencia, especialmente en relación con la ambivalencia de los factores del denominado "aislamiento migratorio". Las redes formales o informales en las que participa la víctima pueden tener efectos diversos en la gestión del riesgo y/o de la violencia porque también pueden causar victimización primaria o convertirse en agentes o contexto de legitimación de los agresores. No obstante, también pueden ser agentes y espacios que coadyuvan o participan de la gestión del riesgo.

Si se conciben estas redes como espacios y agentes de interacción, aunque externos - y siempre que las decisiones de la víctima prevalgan-, la capacidad de gestión de la víctima se refuerza. Además, en caso de implicar otros agentes sociales, como las ONGs o asociaciones de migraciones, se produce un doble efecto positivo. Primero, se reconoce la condición de interlocutores válidos de estos agentes en la sociedad de recepción, integrando las preocupaciones y aspiraciones de la población migrante. Segundo, se fomenta que se preste una mayor atención e interés a la eliminación de la violencia y se integre la voz de las víctimas si son asociaciones de víctimas.

Las propuestas tendentes a garantizar una gestión colectiva del riesgo, como la intervención activa de agentes sociales de diversa índole (los servicios de atención a la víctima en coordinación con determinados colectivos de migrantes), pretenden también identificar respuestas estratégicas que eviten, en la medida de lo posible, que la condición de inmigrante en situación irregular cause victimización secundaria. No debe olvidarse que se trata de contextos y espacios situados y construidos desde los que se puede combatir la discriminación que causa la victimización secundaria. 


\section{NOTAS CONCLUSIVAS}

En este estudio se han expuesto y analizado situaciones de victimización secundaria que se producen a consecuencia de la implementación de leyes y prácticas institucionales en materia de violencia de género y extranjería. Entendiendo la victimización secundaria como la segunda experiencia victimal de quien previamente ha sido víctima de un delito, esta afecta a las víctimas inmigrantes de violencia de género en situación administrativa irregular con la amenaza de expulsión si denuncian la situación de violencia y al hacerlo ponen en conocimiento de las autoridades policiales dicha irregularidad.

Frente a ello se propone una serie de medidas que pretenden combatir la victimización secundaria, que promueven alternativas a la judicialización en el acceso a los servicios. En primer lugar, la derogación de las disposiciones normativas que disponen el inicio del procedimiento administrativo de expulsión para las víctimas de violencia de género, con mayor razón cuando son contrarias a las disposiciones de la Ley del Estatuto de la Víctima. Así mismo, se debe promover su acceso a la regularidad mediante vías de estabilización ordinarias. De ser así, las normas de extranjerías tendrían como objeto la regularización y no la lógica del control y la amenaza de la expulsión.

En segundo lugar, se proponen medidas de reconocimiento de la situación de violencia por otras vías distintas a la interposición de la denuncia para promover un mayor respeto de la autonomía de la víctima y permitir un acceso a los recursos y servicios públicos. Ya es posible esta acreditación del Ministerio fiscal con carácter excepcional, que pone el énfasis en el acceso a dichos recursos y no limita los derechos de terceros ni vulnera los principios de contradicción, audiencia y defensa. En este sentido, y dado que el Ministerio Fiscal sigue representando cierta institucionalización, creo oportuno reflexionar acerca de la posibilidad de implicar otros operadores cuyos informes podrían acreditar dicha situación. Me refiero a las Unidades especiales de Valoración Integral, compuestas por profesionales que pueden tener indicios sobre la situación de violencia y conocer la situación, aspiraciones y necesidades de las víctimas, ofreciendo un asesoramiento interdisciplinar.

En tercer lugar, he sugerido que se podría permitir la acreditación de esta situación de violencia a asociaciones y organizaciones porque de este modo se promovería que dichas asociaciones atendiesen 
estas situaciones y actuasen en pro de los derechos de las víctimas. Al pensar en colectivos, por ejemplo de mujeres inmigrantes, intento promover cauces, sinergias o simplemente estrategias para combatir la discriminación interseccional que persiste contra mujeres y contra migrantes, que a su vez causa victimización secundaria. Se trata de una reflexión sobre un supuesto muy concreto, pero que considero que explica los caracteres y efectos de esta segunda experiencia victimal. Y he procedido así con objeto de incrementar la confianza de las víctimas en el sistema jurídico más allá de la denuncia, y con mayor razón proponer fórmulas que garanticen un mayor respeto de su autonomía. A mi parecer, en esta dirección debe apuntar una reflexión ulterior y con carácter general sobre el impacto y la eficacia de la LOMPIVG.

\section{BIBLIOGRAFÍA}

ACALE, M. (2006): "Mujeres inmigrantes víctimas de violencia de género en España”. En L. R. Ruiz Rodríguez (coord.), Sistema Penal y exclusión de extranjeros. Albacete, Bomarzo, pp. 127-158.

Acale, M. (2007): "Tratamiento jurídico y social de la mujer inmigrante víctima: modelo español". EGUZKILORE, 21, pp. 203-233.

AÑón, M. J. (2010): "El acceso de las mujeres inmigrantes a los derechos humanos: la igualdad inacabada". En A. Solanes (ed.), Derechos Humanos, Migraciones y Diversidad. Valencia, Publicacions de la Universitat de València, pp. 105-138.

AÑón, M. J. (2013): "Principio antidiscriminatorio y determinación de la desventaja”. Isonomía, 39, pp. 127-157.

AÑón, M. J. (2016): "Violencia con género. A propósito del concepto y la concepción de la violencia contra las mujeres". Cuadernos Electrónicos de Filosofía del Derecho, 33, pp. 1-26.

ArNoso, M. ET ALIA (2012): "Mujer inmigrante y violencia de género: Factores de vulnerabilidad y protección social". Migraciones, 33, pp. 169-200.

Barrère, M. A. y Morondo, D. (2005): "La difícil adaptación de la igualdad de oportunidades a la discriminación institucional: el asunto Gruber del TJCE”. En M. A. BARRÈRE y A. CAMPOS (coord.), Igualdad de oportunidades e igualdad de género: Una relación a debate. Oñati, Instituto Internacional de Sociología Jurídica de Oñati, Dykinson, pp. 143-160.

Crenshaw, K. (1996): "Mapping the Margins: Intersectionality, Identity Politics and Violence Against Women of Color". En K. Weisberg (ed.) Applications of Feminist Legal Theory to Women's Lives. Sex, Violence, Work, and Reproduction. Philadelphia, Temple University Press, pp. 363-377. 
DE LuCAs, J. (2004): “Cómo introducir el principio de justicia en las políticas de inmigración”. En L. Miraut (ed.), Justicia, Migración y Derecho. Madrid, Dykinson, pp. 15-54.

DE LuCAS, J. (2005): “Nuevas estrategias de estigmatización. El Derecho, frente a los inmigrantes”. En G. Portilla (Coord.), Mutaciones de Leviatán. Legitimación de los nuevos modelos penales. Madrid, Akal, pp. 205-219.

Fineman, M. (2011): "Vulnerability, equality and the human condition". En J. Jones ET ALIA (ed.) Gender, Sexualities and Law. Oxon, Routledge, pp. 53-62.

Fineman, M. (2013): "Equality, Autonomy, and the Vulnerable Subject in Law and Politics". En M. Fineman y A. Grear (ed.) Vulnerability. Reflections on a New Ethical Foundation for Law and Politics. Burlington, Ashgate, pp. 13-28.

FIscher, N. (2013): “The detention of foreigners in France: Between discretionary control and the rule of law". European Journal of Criminology, 10(6), pp. 692-708

GARCía, J. ET ALIA (2013): Identificación por perfil étnico en España. Informe sobre experiencias y actitudes en relación con las actuaciones policiales. Valencia, Tirant lo Blanch.

Gutiérrez, C., Coronel, E. y Andrés, C. (2009): "Revisión teórica del concepto de victimización secundaria”. LIBERABIT, 15 (1), pp. 49-58.

IBÁÑEZ, M. (2012): “Algunas consideraciones sobre la prueba en los delitos de violencia de género”. En E. MARTínez (Dir.), La Prevención y Erradicación de la Violencia de Género. Un estudio multidisciplinar y forense. Cizur Menor, Thomson Reuters Aranzadi, pp. 435-456.

La SpINA, E. (2009): "El criterio de "adecuación” aplicado al derecho a la vivienda de los inmigrantes: una geometría variable”. Migraciones, 26, pp. 41-83.

La Spina, E. y Merino, V. M. (2012): Limitando derechos. La reagrupación familiar y el derecho de asilo por violencia de género. Alcalá de Henares, Cuadernos Democracia y Derechos Humanos, Ed. Universidad de Alcalá de Henares.

LARRAURI, E. (2005): “¿Se debe proteger a la mujer contra su voluntad?”. Cuadernos Penales José María Lidón. La ley de medidas de protección integral contra la violencia de género, 2, Universidad de Deusto, pp. 157-182.

Larrauri, E. (2007): Criminología Crítica y Violencia de Género. Madrid, Colección Estructuras y Procesos, Trotta.

LARRAuri, E. (2016): “Antecedentes penales y expulsión de personas inmigrantes”. InDret, Revista para el Análisis del Derecho, 2/2016, pp. 1-29.

LóPEZ, R. (2013): "Mujer inmigrante víctima de violencia de género". REDUR, 11, pp. 199-229.

López, M. y Montiel, G. (2012): "Modelos explicativos y sistemas de indicadores para entender y medir la violencia de género”. En E. MarTínez (Dir.), La Prevención y Erradicación de la Violencia de Género. Un estudio multidisciplinar y forense. Cizur Menor, Thomson Reuters Aranzadi, pp. 77-96. 
Maqueda, M. L. (2008): “¿Es la estrategia penal una solución a la violencia contra las mujeres? Algunas respuestas desde un discurso feminista crítico?”. En P. Laurenzo, M. L. Maqueda y A. Rubio (coord.), Género, violencia y derecho. Valencia, Tirant Monografías, pp. 363-408.

Martínez, M. (dir.) (2013): Mujeres en el CIE: género, inmigración e internamiento. Proyecto I+D+i Iusmigrante: Iuspuniendi e inmigración irregular. Ed. Gakoa.

Martínez, E. (2008): "La protección cautelar penal de las víctimas de violencia de género”. En C. Villacampa (coord.), Violencia de género y sistema de justicia penal. Valencia, Tirant lo Blanch, pp. 319-370.

Morillas, D., Patró, R. y Aguilar, M. (2014): Victimología: Un estudio sobre la víctima y los procesos de victimización. Madrid, Dykinson.

Monteros, S. (2008): "La violencia de las fronteras legales: Violencia de género y mujer inmigrante”. En P. Laurenzo, M. L. Maqueda y A. Rubio (coord.), Género, violencia y derecho. Valencia, Tirant Monografías, pp. 231-249.

Montesinos, A. (2012): "La Dispensa de la obligación de declarar según el artículo 416 LECRIM”. En E. MARTínez (Dir.), La Prevención y Erradicación de la Violencia de Género. Un estudio multidisciplinar y forense. Cizur Menor,Thomson Reuters Aranzadi, pp. 391-412.

Parella, S. (2003): Mujer, inmigrante y trabajadora: la triple discriminación. Barcelona, Anthropos, Serie Migraciones.

Peramato, T. (2015): “Aspectos jurídicos de la violencia de género. Evolución”. Cuadernos de la Guardia Civil, 51, pp. 8-25.

Pereda, N. y TAmarit, J. M. (2013): "La victimización de las personas inmigrantes”. En N. Pereda y J. M. Tamarit (ed.), Victimología. Teórica y Aplicada. Barcelona, Huygens, pp. 273-294.

Рітсн, T. (2003): Un derecho para dos. La construcción jurídica de género, sexo y sexualidad. Madrid, Trotta.

Rubio, A. y Moya, M. (2011): "La ciudadanía en Europa y el fenómeno migratorio: nuevas desigualdades y servidumbres voluntarias”. Anales de la Cátedra Francisco Suárez, 45, pp. 183-227.

RuedA, R. (2008): "Mujer extranjera víctima de violencia de género y derecho de extranjería”. Revista de Derecho Migratorio y Extranjería, 18, pp. 81117.

Salinero, S. (2011): "La expulsión de extranjeros en el derecho penal. Una realidad en España, una posibilidad en Chile”. Política Criminal, 6 (11), pp. 106-141.

Solanes, A. (2006): "Integración sin derechos: de la irregularidad a la integración”. Cuadernos Electrónicos de filosofía del Derecho, 14, pp. 1-24.

Solanes, A. (2015): "Rights, Immigration and Social Cohesion in Spain". Migraciones Internacionales, 8 (2), pp. 9-40.

Sos Racismo (2015): Informe Anual 2015. Sobre el racismo en el Estado español. San Sebastián, SOS Racismo. 
TAmarit, J. M. (2013): “La victimización de las personas migrantes”. En N. Pereda y J. M. Tamarit (ed.), Victimología. Teórica y Aplicada. Barcelona, Huygens, pp. 273-294.

Ugelvik, S. y UgelviK, T. (2013): "Immigration control in Ultima Thule: Detention and exclusion, Norwegian style". European Journal of Criminology, 10(6), pp. 709-724.

Villacampa, C. y Torres, N. (2012): “Mujeres víctimas de trata en prisión en España”. Revista de Derecho Penal y Criminología, 8, pp. 411-494.

Women's Link Worldwide (2012): Mujeres en los Centros de Internamiento de Extranjeros (CIE) Realidades entre rejas. Madrid, WLW. 